\title{
Deposit buildup on prosthetic eye material (in vitro) and its effect on surface wettability
}

This article was published in the following Dove Press journal:

Clinical Ophthalmology

12 February 2013

Number of times this article has been viewed

\author{
Keith Raymond Pine' \\ Brian Sloan ${ }^{2}$ \\ KyuYeon Ivy Han' \\ Simon Swift ${ }^{3}$ \\ Robert John Jacobs' \\ 'Department of Optometry and Vision \\ Science, New Zealand National Eye \\ Centre, The University of Auckland, \\ Auckland, New Zealand; ${ }^{2} \mathrm{New}$ \\ Zealand National Eye Centre, The \\ University of Auckland, Auckland, New \\ Zealand; ${ }^{3}$ Department of Molecular \\ Medicine and Pathology, School \\ of Medical Sciences, The University \\ of Auckland, Auckland, New Zealand
}

Correspondence: Keith Raymond Pine Department of Optometry and Vision Science, New Zealand National Eye Centre, The University of Auckland, Private Bag 92019, Auckland II42. New Zealand

Tel +6493737999

Email keith.pine@kp-assoc.co.nz
Background: The aim of this in-vitro study was to investigate the effect of different polishing standards on prosthetic eye material (poly(methyl methacrylate) [PMMA]) on surface wettability and the rate of protein and lipid buildup.

Methods: Sample disks ( $12 \mathrm{~mm}$ diameter $\times 1 \mathrm{~mm}$ thickness $)$ of PMMA were polished to three different standards of surface finish: low, normal, and optical quality contact lens standard. The sample disks were incubated in a protein-rich artificial tear solution (ATS) for the following periods of time: 1 second, 30 minutes, 1 hour, 4 hours, 24 hours, and 14 days. Surface wettability was measured with a goniometer before and after protein deposits were removed. One-way analysis of variance and paired-samples $t$-test were used for the statistical analysis.

Results: Between 13.64 and $62.88 \mu \mathrm{g}$ of protein adhered to the sample disks immediately upon immersion in ATS. Sample disks with the highest polish attracted less protein deposits. The sample disks polished to optical quality contact lens standard were more wettable than those less highly polished, and wettability significantly decreased following removal of protein deposits. The addition of lipids to protein-only ATS made no difference to the amount of protein deposited on the sample disks for any of the standards of surface polish tested.

Conclusion: The findings are consistent with the results of the in-vivo investigation reported previously by the authors. Our view that the minimum standard of polish for prosthetic eyes should be optical quality contact lens standard and that deposits on PMMA prosthetic eyes improve the lubricating properties of the socket fluids has been reinforced by the results of this study.

Keywords: protein deposits, surface polish, PMMA

\section{Introduction}

The presence of surface deposits on prosthetic eyes has been found to be associated with less conjunctival inflammation and less mucoid discharge, but a causal link for this association was not established at the time. ${ }^{1}$ In a recent study designed to find a likely causal link, ${ }^{2}$ we reviewed the contact lens literature and described the nature of deposit build-up on prosthetic eyes (in vivo) and how the rate of deposition and the wettability of prosthetic eye surfaces was influenced by the standard of surface polish. We also reported that prostheses polished to optical quality contact lens standard had surfaces that were more wettable than those polished normally and that removal of deposits significantly decreased surface wettability and was a contributing factor to increased conjunctival inflammation and mucoid discharge. ${ }^{2}$

The current study approaches the topic of deposition on prosthetic eyes from a different perspective using in-vitro experiments to explain some of the in-vivo results and to 
broaden the evidence base for the major findings in the earlier investigations. We also address our reservation that goniometric measurements of wettability made on the curved surfaces of a prosthetic eye may not be as reliable as those from flat surfaces. In this study, we set out to determine whether surface wettability and rates of protein deposition are affected by different poly(methyl methacrylate) (PMMA) surface finishes as they were in the in-vivo experiments. ${ }^{2}$ We also compare the characteristics of deposits on different contact lens materials with deposits on PMMA by following the methods of Bontempo and Rapp ${ }^{3}$ as closely as possible and by using sample disks with similar surface areas to contact lenses.

The specific aims were to: (a) investigate the amount of protein deposited on prosthetic eye material (PMMA) with different surface finishes immersed in protein-only artificial tear solution (ATS) for different periods of time; (b) investigate the amount of protein deposited on PMMA with different surface finishes immersed in protein/lipid ATS for different periods of time; (c) compare the results of investigations ( $a$ and $b$ ) with the results of Bontempo and Rapp ${ }^{3,4}$ who tested different contact lens materials in protein-only and protein/lipid ATS; and (d) determine the effect of protein deposits on the wettability of PMMA material polished to different standards of finish.

\section{Methods}

\section{Preparation of samples of prosthetic eye material}

The sample disks for the experiments in this study were manufactured from a single mix of Vertex ${ }^{\mathrm{TM}}$ heat cure (Vertex Dental, Zeist, The Netherlands), clear PMMA ${ }^{5}$ prepared using 1 part monomer (liquid) to 2.5 parts polymer (powder). The PMMA was placed in a plaster-of-Paris mold made from $12 \mathrm{~mm}$ diameter rod shaped patterns and polymerization was completed in a water curing tank. The water was brought to the boil over a 30 minute period and held at $100^{\circ} \mathrm{C}$ for 20 minutes before being allowed to cool to room temperature. The $1 \mathrm{~mm}$ thick sample disks were cut from the resultant PMMA $12 \mathrm{~mm}$ diameter rods before being trimmed and polished to the required finishing grades. Dental laboratory pumice (medium grade) (Henry Schein ${ }^{\circledR}$; Henry Schein, Inc, Melville, NY, USA $)^{6}$ applied with a wet calico polishing mop (Buff Flannel 3 × 20 Ply, Item Code 9004230; Henry Schein, Inc $)^{7}$ was used to achieve the low polish grade. A polishing compound for dental plastics final polish (Bego, Lincoln, RI, USA $)^{8}$ was applied with a dry calico polishing mop to achieve the normal polish grade. The Bego product is no longer in production but is similar to other commercially available denture polishing compounds. Aluminium oxide paste, obtained from Hirstlens NZ Ltd (Eden Terrace, Auckland, New Zealand $)^{9}$ was applied with a rotating foam polyurethane cone to achieve the optical quality contact lens polish grade.

\section{Rate of deposition on low-, normal-, and high-polished PMMA}

The PMMA sample disks were decontaminated by wiping with a tissue soaked in $70 \%$ ethanol and sorted into sets of six containing two with low-, two with normal-, and two with high-grade standards of polish. Each set of six was immersed in protein-only ATS or protein/lipid ATS. The protein-only ATS contained human albumin, lysozyme, and lactoferrin (each from Sigma-Aldrich, St Louis, MO, USA) at concentrations used by Bontempo and Rapp., ${ }^{3,4}$ The protein/lipid combination ATS was made by adding $20 \mu \mathrm{L}$ of a $25 \mathrm{mg} / \mathrm{mL}$ lipid standard (Non Polar Lipid Mix-B; Matreya LLC, PA, USA) containing an equal mix by weight of cholesteryloleate, methyoleate, triolein, oleic acid, and cholesterol in chloroform to $20 \mathrm{~mL}$ of the protein-only ATS. For immersion studies, $400 \mu \mathrm{L}$ of the ATS at $37^{\circ} \mathrm{C}$ was contained within a sterile $5 \mathrm{~mL}$ polypropylene tube (Sarstedt AG and Co, Nümbrecht, Germany). A single disk was immersed in each tube. The sets of sample disks were removed from immersion tubes after approximately 1 second, 30 minutes, 1 hour, 4 hours, 24 hours, or 14 days. Sample disks were incubated at $37^{\circ} \mathrm{C}$ with constant agitation at $100 \mathrm{rpm}$ using an Innova ${ }^{\circledR} 40$ Incubator Shaker (New Brunswick Scientific Co, Edison, NJ, USA). After each period of incubation, the immersion ATS was removed and the sample disks rinsed with sterile saline $(0.85 \% \mathrm{w} / \mathrm{v} \mathrm{NaCl})$ and then placed in $200 \mu \mathrm{L} 1 \mathrm{M}$ Tris $\mathrm{HCl}$ buffer ( $\mathrm{pH}$ 6.8), which was then heated to $70^{\circ} \mathrm{C}$ for 10 minutes to extract any bound proteins from the surface of the sample disk. The protein concentration in the extraction buffer was determined using the Microplate procedure of the Pierce ${ }^{\circledR}$ BCA Protein Assay Kit (Thermo Scientific, Waltham, MA, USA) using the manufacturer's instructions.

\section{Wettability of PMMA with different surface finishes}

PMMA sample disks with low, normal, and high surface polishes were decontaminated by wiping with a tissue soaked in $70 \%$ ethanol, allowed to dry, and set up in a goniometer (Cam 101; KSV Instruments, Bridgeport, CT, USA). ${ }^{10}$ A goniometer is a video-based instrument that captures the image of a standard droplet of liquid dispensed with a syringe onto a specimen surface. It then measures the angle formed at the interface between the edge of the droplet of liquid and the surface - the wetting angle. 
In this experiment, wetting angles were measured using distilled water droplets dispensed onto the surface of the sample PMMA disks. The average of right and left angles for each droplet was calculated for each disk and finally, averages were calculated for ten sample disks for each of the three polish standards. For sample disks immersed in ATS for 24 hours, each disk was blotted dry with a tissue paper before measurement of the wetting angle. Each disk was then firmly wiped clean with a wetted paper towel (the same method used in our in-vivo experiment ${ }^{2}$ ), before a further measurement of the wetting angle was made and average wetting angles were calculated.

One-way analysis of variance and paired samples $t$-test were used for the statistical analysis.

\section{Results}

\section{Rates of deposition on low, normal, and high polished PMMA}

There was a significant difference between the amount of protein and standard of polish for all time periods ( $\mathrm{F}=57.98, P=0.0001)$. Sample disks polished to the optical quality contact lens standard attracted significantly less protein than low (mean difference $-49.24(\mu \mathrm{g})$, standard deviation $[\mathrm{SD}] 4.82,95 \%$ confidence interval $[\mathrm{CI}]-62.23$ to $-36.25, P<0.0001$ ) or normally polished disks (mean difference $-38.89(\mu \mathrm{g})$, SD $4.82,95 \% \mathrm{CI}-51.88$ to -25.90 , $P<0.0001)$. There was no difference between total protein on low polished surfaces than on normally polished surfaces (mean difference $10.35(\mu \mathrm{g}), \mathrm{SD} 4.82,95 \% \mathrm{CI}-2.63$ to $23.34, P<0.146$ ) (Figure 1).

Total protein extracted from the sample disks after immersion in protein-rich ATS did not increase over the 2 weeks of incubation on disks polished to low and normal standards, and fluctuated on disks polished to the optical quality contact lens standard (Figure 1).

PMMA disks with low, normal, and optical quality standards of finish are compared with those of Bontempo and Rapp in Table 1. No relationship appeared to exist between total protein extracted from contact lens materials and PMMA, and the addition of lipids to protein-only ATS made no difference to the amount of protein extracted on the sample disks for any of the standards of surface polish examined.

\section{Wetting angles of PMMA with different surface finishes}

The average wetting angles for the different polishing standards were $86.8^{\circ}\left(\mathrm{SD} 4.9^{\circ}\right)$ for low polish, $92.9^{\circ}$

\section{Total protein on sample disks in protein-only solution VS time intervals}

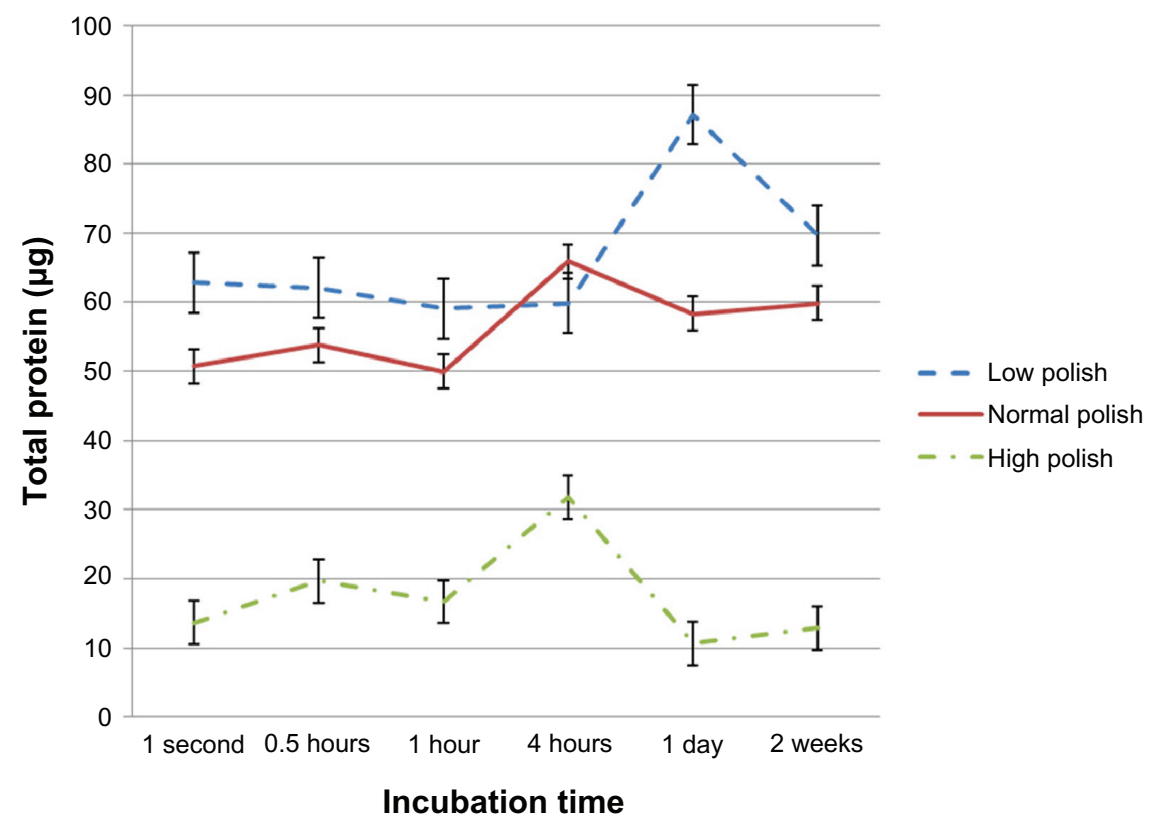

Figure I Total protein extracted from the surface of PMMA disks ( $12 \mathrm{~mm}$ diameter, I mm thick) finished to low, normal, and high (optical quality contact lens standard) standards of polish as a function of incubation time in protein-rich artificial tear solution.

Note: Bars indicate standard error.

Abbreviation: PMMA, poly(methyl methacrylate). 
Table I A comparison of total protein extracted from the surface deposits of PMMA disks incubated for 24 hours in (I) protein-only ATS and (2) protein/lipid ATS

\begin{tabular}{|c|c|c|c|c|c|}
\hline Material & $\begin{array}{l}\text { Total protein extracted from } \\
\text { protein-only ATS }(\mu \mathrm{g}) \text { mean } \pm \\
\text { standard error of the mean }\end{array}$ & $\mathbf{n}$ & $\begin{array}{l}\text { Total protein extracted } \\
\text { from protein/lipid ATS } \\
(\mu \mathrm{g}) \text { mean } \pm \text { standard } \\
\text { error of the mean }\end{array}$ & $\mathbf{n}$ & $\begin{array}{l}P \text {-value (paired } \\
\text { sample } t \text {-test) }\end{array}$ \\
\hline PMMA low polish & $87.12 \pm 3.79$ & 2 & $58.33 \pm 0.76$ & 2 & 0.067 \\
\hline PMMA normal polish & $58.33 \pm 7.58$ & 2 & $49.24 \pm 3.03$ & 2 & 0.55 \\
\hline $\begin{array}{l}\text { PMMA high (optical quality contact } \\
\text { lens) polish }\end{array}$ & $10.61 \pm 6.06$ & 2 & $6.82 \pm 0.76$ & 2 & 0.68 \\
\hline \multicolumn{6}{|l|}{ Hydrophilic lens } \\
\hline Lens group I & $9.06 \pm 1.05$ & 8 & $6.95 \pm 0.67$ & 8 & Ns \\
\hline Lens group II & $23.94 \pm 15.9$ & 8 & $10.35 \pm 2.52$ & 8 & Ns \\
\hline Lens group III & $7.59 \pm 1.87$ & 8 & $|5.3| \pm 1.79$ & 8 & Ns \\
\hline Lens group IV & $157.66 \pm 6.69$ & 8 & $91.64 \pm 18.74$ & 8 & 0.0009 \\
\hline Siloxanyl alkyl acrylate RPG lens & $1.54 \pm 0.26$ & 12 & $6.82 \pm 0.39$ & 12 & 0.0023 \\
\hline Fluorosiloxanyl alkyl acrylate RPG lens & $3.76 \pm 0.57$ & 12 & $13.42 \pm 0.69$ & 12 & $<0.000$ I \\
\hline
\end{tabular}

Note: The results for contact lens materials reported by Bontempo and Rapp (1997) are shown for comparison in the non-highlighted rows of the table. Abbreviations: ATS, artificial tear solution; PMMA, poly(methyl methacrylate); RPG, rigid gas permeable.

(SD 9.6 $6^{\circ}$ for normal polish, and $71.9^{\circ}$ (SD 9.2 $2^{\circ}$ ) for high (contact-lens standard) polish. There was a significant difference between wetting angles and standard of polish (F $=17.42, P=0.0001)$ The average wetting angle of PMMA polished to the optical quality contact lens standard was significantly lower (the surface was more wettable) than for low (mean difference $-14.92^{\circ}$, SD 3.66, 95\% CI -24.27 to $-5.56, P=0.001$ ) or normally polished surfaces (mean difference $-21.02^{\circ}, \mathrm{SD} 3.66,95 \% \mathrm{CI}-30.37$ to $-11.66, P=0.0001)$. There was no difference between the wetting angles on low or normally polished PMMA (mean difference $-6.10^{\circ}$, SD $3.66,95 \% \mathrm{CI}-15.45$ to 3.25 , $P=0.322)$ (Figure 2).

\section{Wetting angles of PMMA with different surface finishes before and after protein deposition}

The average wetting angles after 24 hours of incubation in ATS were significantly lower than before incubation. After the PMMA coupons were cleaned, the wetting angles returned to their pre-incubation levels (Table 2 and Figure 3).

\section{Discussion}

The PMMA sample disks used in this study were made from the same material used for the manufacture of prosthetic eyes. The material is also the same as that used in the manufacture of dentures and is sourced from dental supply companies. The low finish and normal finish polishing agents were chosen because they are commonly used for finishing dentures in dental laboratories and by extension for prosthetic eyes. The laboratory pumice used to achieve the low polish level removes tooling marks left by abrasive arbor bands used to trim PMMA. The normal polish is the usual standard of finish for dentures and most prosthetic eyes (at least in New Zealand). The optical quality contact lens polishing technique is the common technique for polishing hard contact lenses and has been recommended for prosthetic eye polishing by Joseph LeGrand. ${ }^{11}$

There have been numerous studies of lipid and/or protein deposition on contact lens materials ${ }^{12-14}$ but no investigations of deposits on prosthetic eye material appear to have been carried out. Bontempo and Rapp ${ }^{3,4}$ investigated protein-lipid interactions responsible for surface deposition on four types of hydrophilic (soft) contact lenses and two types of rigid gas permeable (RGP) contact lenses. They found that the presence of lipid in ATS enhances protein deposition on both types of RGP contact lens materials examined, but reduces protein deposition on type IV hydrophilic lens materials. The presence of lipids makes no difference to protein deposition on type I, II, or III soft lens materials. In this study we followed the methods used by Bontempo and Rapp as closely as possible by using sample disks with similar surface areas to contact lenses and using similar artificial tear solutions and incubation time. Our motivation was to determine whether or not adding lipid to the protein-only ATS made a difference to the rate of protein deposition on PMMA and to compare total protein extracted from PMMA with the total protein extracted from contact lens materials. It is not surprising that no relationship appears to exist between the findings of the two studies because protein deposition is driven by the composition, charge, and water content of the different contact lens materials, ${ }^{15}$ and clearly, PMMA is different from 
Wetting angle Vs surface finish

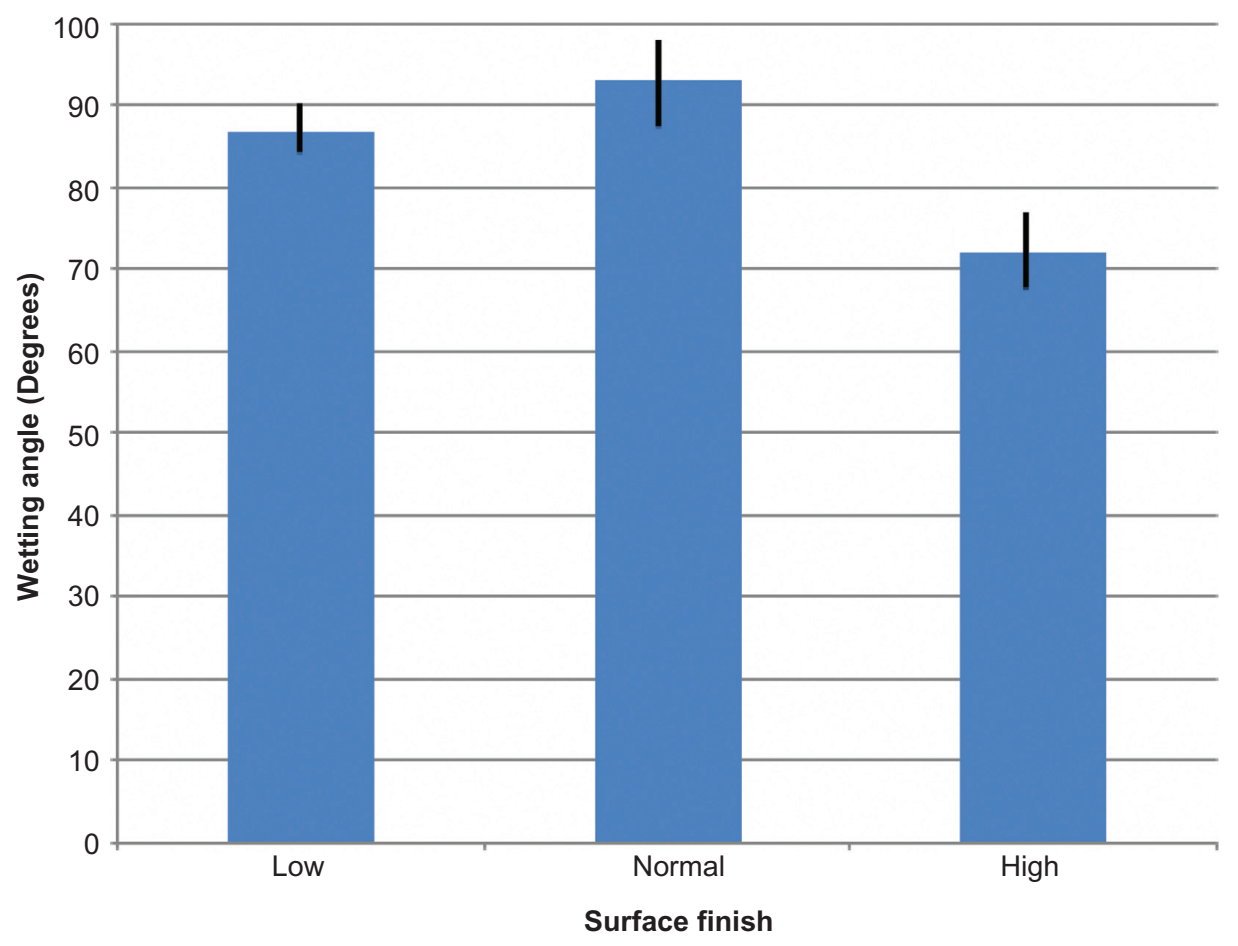

Figure 2 Wetting angles of different PMMA surface finishes.

Notes: High wetting angles indicate that surfaces are less wettable than surfaces with low wetting angles. Bars indicate standard deviation. Abbreviation: PMMA, poly(methyl methacrylate).

the materials tested by Bontempo and Rapp. ${ }^{3,4}$ Similarly, adding lipids to the protein-only ATS made no apparent difference to the rate of protein deposition in this study.

The finding that sample disks polished to optical quality contact lens standard (high polish) attracted less protein than normally polished surfaces after 2 weeks in ATS may be compared to the observation that prosthetic eyes polished to the same high standard accumulated deposits at slower rates than normally polished prosthetic eyes after 2 weeks of continuous wear. ${ }^{2}$ These results suggest that adherence of deposits depends on the fineness of the surface matrix compared with the size of protein molecules, with the protein molecules adhering more readily to rougher surfaces. Surface matrix fineness also appears to influence contact lenses deposition where deposits have been shown to take longer to build up on rigid gas permeable lenses than on hydrogel lenses, which have a higher surface matrix porosity. ${ }^{16}$

The finding that sample disks polished to optical quality contact lens standard had greater wettability compared with normally polished disks may be compared to the findings that prosthetic eyes polished to optical quality contact lens standard also had greater wettability. ${ }^{2}$ Also, the reduction in wettability that occurred when protein deposits were removed from the sample disks after 24 hours of incubation in ATS may be compared to the finding that wettability reduced significantly when deposits were removed from prosthetic eyes. ${ }^{2}$ The underlying mechanisms for the effects of different surface finishes on the wettability of various materials have

Table 2 Average wetting angles of PMMA surfaces polished to low, normal, and high (contact lens) standards after incubation in protein-only artificial tear solution and after protein deposits were removed

\begin{tabular}{|c|c|c|c|c|c|c|}
\hline $\begin{array}{l}\text { Standard } \\
\text { of surface } \\
\text { polish } \\
\end{array}$ & $\begin{array}{l}\text { Wetting angle after } \\
\text { deposition and before } \\
\text { cleaning }\end{array}$ & SD & $\begin{array}{l}\text { Wetting angle after } \\
\text { removal of deposits }\end{array}$ & SD & Difference & $\begin{array}{l}\text { P-value } \\
\text { (paired } \\
\text { t-test) } \\
\end{array}$ \\
\hline Low & $27.26^{\circ}$ & 17.53 & $77.73^{\circ}$ & 3.02 & $50.47^{\circ}$ & 0.003 \\
\hline Normal & $14.07^{\circ}$ & 6.85 & $77.37^{\circ}$ & 4.83 & $63.30^{\circ}$ & $<0.0001$ \\
\hline High & $14.08^{\circ}$ & 11.19 & $68.48^{\circ}$ & 5.97 & $54.40^{\circ}$ & $<0.0001$ \\
\hline
\end{tabular}

Abbreviations: PMMA, poly(methyl methacrylate); SD, standard deviation. 


\section{Wetting angle Vs surface finish with and without protein deposits}

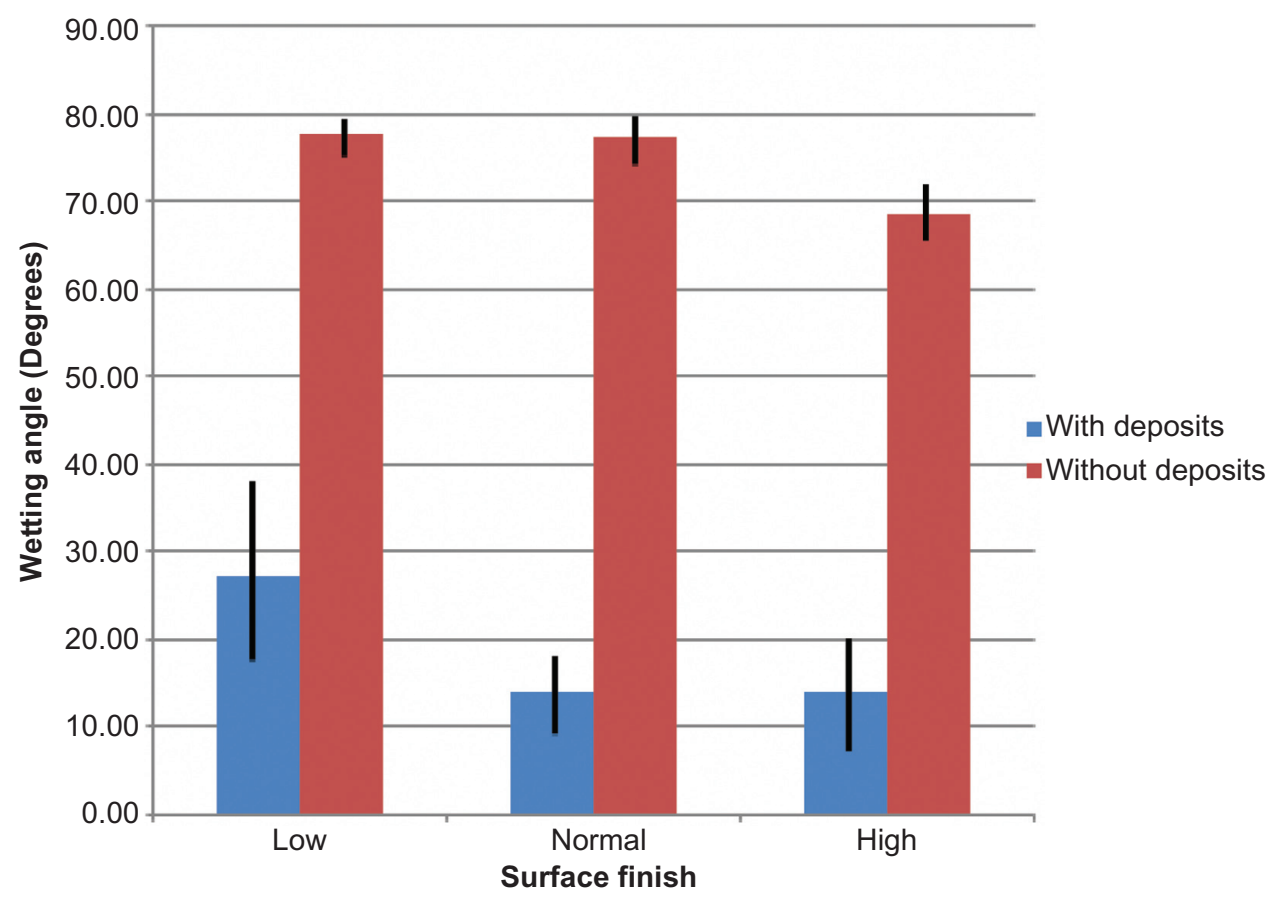

Figure 3 Average wetting angles of surfaces polished to low, normal, and high standards after incubation in protein-only artificial tear solution and before and after protein deposits on the material was removed.

Note: Bars indicate standard deviation.

been well documented elsewhere. For example, Uelzen and Müller investigated wettability enhancement by rough surfaces generated by thin film technology. ${ }^{17}$

Finally, the finding that protein was able to be extracted from the surface of the sample PMMA disks 1 second after immersion in protein-rich ATS appeared to correlate with the in-vivo result that wettability increased after 10 minutes of prosthetic eye wear following reinsertion after polishing. ${ }^{2}$

Not all the results of the in-vitro tests were comparable to the in-vivo results. Deposits on sample disks did not accumulate over time as they did on prosthetic eyes worn continuously. ${ }^{2}$ This may be an example where in-vitro results are not directly transferrable to the in-vivo state because the conditions of incubation in ATS are not the same as those in the anophthalmic socket. In particular, the deposits may not have accumulated over time because the constant agitation of the ATS disturbed the settling process.

Understanding the effects of different surface finishes and the presence of protein deposits on PMMA material has implications for clinical practice. Our view that the minimum standard of polish for prosthetic eyes should be optical quality contact lens standard ${ }^{2}$ and that deposits on PMMA prosthetic eyes improve the lubricating properties of the socket fluids have been reinforced by the results of this study. ${ }^{2}$

\section{Conclusion}

Overall, the findings in this novel study provide useful insights as to how different surface finishes on PMMA materials affect protein deposition and surface wettability. The findings are consistent with the results of the in-vivo investigation reported previously. ${ }^{2}$ They reassure us that the curved surface of the prosthetic eye did not cause spurious wetting angle results and reinforce the conclusion that an optical quality contact lens standard should be the minimum standard of finish for prosthetic eyes. This standard is particularly important for the interpalpebral surface of the prosthesis where it may facilitate the smooth action of the eyelids and the cleansing action of tears. In the retropalpebral area, this standard also assists the lubricating function of tears when the prosthesis is first inserted into the socket and before tear protein deposits become established. Once established, the deposits facilitate the lubricating properties of the socket fluids.

\section{Disclosure}

The authors report no conflicts of interest in this work.

\section{References}

1. Pine K, Sloan B, Stewart J, Jacobs RJ. The response of the anophthalmic socket to prosthetic eye wear. Clin Ophthalmol. 2012;6:707-713. 
2. Pine KR, Sloan B, Jacobs RJ. Deposit buildup on prosthetic eyes and the implications for conjunctival inflammation and discharge. Clin Ophthalmol. 2012;6:1755-1762.

3. Bontempo AR, Rapp J. Protein-lipid interaction on the surface of a rigid gas-permeable contact lens in vitro. Curr Eye Res. 1997;16(12): $1258-1262$.

4. Bontempo AR, Rapp J. Protein-lipid interaction on the surface of a hydrophilic contact lens in vitro. Curr Eye Res. 1997;16(8):776-781.

5. Vertex Dental. Available from: http://www.vertex-dental.com/en/ products/18-en/26/142-vertex-trade-rapid-simplified/. Accessed November 20, 2012

6. Henry Schein. Lab pumice. Available from: http://www.henryschein.com/ us-en/Search.aspx?searchkeyWord=pumice. Accessed November 20, 2012.

7. Henry Schein Dental. Buff Flannel $3 \times 20$ Ply. Item Code: 9004230 . Available from: http://www.henryschein.com/us-en/Shopping/ ProductDetails.aspx ?productid $=9004230 \&$ CatalogName $=$ DENTAL $\&$ promoco. Accessed November 20, 2012.

8. Bego [homepage on the Internet]. Acrylic polish. Lincoln, RI: Bego USA; 2012. Available from: http://begousa.com. Accessed November 24, 2012 .
9. Hirstlens NZ Ltd. Contact lens polish. Available from: http://www. hirstlens.co.nz. Accessed November 20, 2012.

10. KSV Instruments. Goniometer Cam 101. Available from: http:// users.metropolia.fi/ karisv/Nanopinta/CAM101.pdf. Accessed November 20, 2012.

11. LeGrand JA. Chronic exudate: an unnecessary evil. J Ophthalmic Prosthet. 1999;4(1):33-40.

12. Fowler SA, Korb DR, Finnemore VM, Allansmith MR. Surface deposits on worn hard contact lenses. Arch Ophthalmol. 1984;102(5):757-759.

13. Franklin VJ, Tighe BJ. Hydrogel lens spoliation. The structure and composition of white spot deposits. Optician. 1991;202:18-23.

14. Franklin VJ. Cleaning efficacy of single-purpose surfactant cleaners and multi-purpose solutions. Cont Lens Anterior Eye. 1997;20(2):63-68.

15. Lorentz H, Jones L. Lipid deposition on hydrogel contact lenses:how history can help us today. Optom Vis Sci. 2007;84(4):286-295.

16. Franklin VJ, Tigue B, Tonge S, Contact lens care: Part 4 - Contact lens deposition, discolouration and spoilation mechanisms. Optician. 2001;222(5808):16-26.

17. Uelzen T, Müller J. Wettability enhancement by rough surfaces generated by thin film technology. Thin Solid Films. 2003;434:311-315.
Clinical Ophthalmology

\section{Publish your work in this journal}

Clinical Ophthalmology is an international, peer-reviewed journal covering all subspecialties within ophthalmology. Key topics include: Optometry; Visual science; Pharmacology and drug therapy in eye diseases; Basic Sciences; Primary and Secondary eye care; Patien Safety and Quality of Care Improvements. This journal is indexed on

Submit your manuscript here: http://www.dovepress.com/clinical-ophthalmology-journal

\section{Dovepress}

PubMed Central and CAS, and is the official journal of The Society of Clinical Ophthalmology (SCO). The manuscript management system is completely online and includes a very quick and fair peer-review system, which is all easy to use. Visit http://www.dovepress.com/ testimonials.php to read real quotes from published authors. 